\title{
Inclusive Education from the Teachers' Perspectives in Palestine
}

\author{
Alaa A. Aladini \\ Islamic University-Gaza, Gaza, Palestine \\ Email: alaaeng2000@gmail.com
}

How to cite this paper: Aladini, A. (2020) Inclusive Education from the Teachers' Perspectives in Palestine. Creative Education, 11, 2443-2457.

https://doi.org/10.4236/ce.2020.1111179

Received: September 9, 2020

Accepted: November 22, 2020

Published: November 27, 2020

Copyright (c) 2020 by author(s) and Scientific Research Publishing Inc. This work is licensed under the Creative Commons Attribution International License (CC BY 4.0).

http://creativecommons.org/licenses/by/4.0/

\begin{abstract}
The current study aimed at investigating the concept of inclusive education, the degree of implementing it in Palestine Schools. Additionally, the study handles the challenges that the school staff members face when implementing inclusive education in their schools. To achieve the study aims, the researcher used the descriptive approach. The researcher interviewed 30 teachers who were chosen from ten random United Nations relief and Works Agency (UNRWA) schools in the middle area of the Gaza Strip. The interview included six questions. The results were positive as the teachers employ the inclusive education initiative tools effectively. Teachers showed the obstacles they face when employing inclusion and they suggested some strategies and solutions to overcome such obstacles. The researcher recommends that stakeholders should provide school staff with suitable training of this initiative and equip schools with instruments and tools that help employ the initiative effectively.
\end{abstract}

\section{Keywords}

Inclusive Education, Vulnerability, Exploitation, UNRWA

\section{Introduction}

Inclusive Education is considered a pivotal issue that Ministry of Education strives to implement in Palestine. This is to achieve social equality and justice. Rodriguez (2019) assures that the implementation of inclusive education has a real challenge due to the lack of awareness for the teachers and the parents as well. In addition, he adds that the resources and materials used for teaching are not accessible to all types of students. In 1994, Education for all program was adopted by the Ministry and then in 1997. Inclusive Education was concerned with those marginalized categories of children to include them in education 
regardless totheir gender or disability.

Education for all children is one of the most essential issues that UN tries to achieve. Under its auspices, a number of international agencies work hard to improve educational opportunities for learners with disabilities. These include: the Department of Economic and Social Affairs (UN DESA), the World Bank, the World Health Organization, the United Nations Educational, Scientific and Cultural Organization (UNESCO) and the United Nations Children's Fund (UNICEF) and the United Nations Relief and Works Agency (UNRWA). The work of all these agencies operates within the framework of the various international standard instruments, as well as programmes and action plans (UNRWA, 2013).

UNRWA, as a refugee agency working in Palestine territories, recently started a reform strategy 2011-2015. One basic component of this strategy is inclusive education so as to make sure that all children have quality education regardless of their mental abilities, gender; and social, health, psychological and economic conditions. UNRWA seeks to achieve inclusion in education for the marginalized and excluded categories of people as disabled and those who need additional education needs (UNRWA, 2011).

The study aims:

- Investigating the degree of implementing inclusive education in UNRWA schools in Palestine.

- Identifying the challenges that schools face when applying inclusion of all children.

- Suggesting solutions of the best ways to employing inclusive education.

The study question is:

To what extent is inclusive education practices employed in UNRWA schools in the Middle Area of Gaza strip by teachers after their exposure to a training program based on inclusive education?

The sub-question is:

1) To what extent do school staff employ inclusive education in UNRWA schools in the Middle Area of Gaza strip?

2) What are the obstacles that UNRWA schools face when employing inclusive education?

3) What are the suggested solutions to improve employing the inclusive education better?

The importance of the study is:

1) Providing UNRWA Education department stakeholders with feedback about the degree of implementing the inclusive education initiative in their schools.

2) Arousing the awareness of the teachers to the solutions of challenges they face regarding inclusive education.

3) Enriching educational research with a serious new neglected issue.

The study terms definitions

UNRWA: it was created in December 1949, the United Nations Relief and 
Works Agency for Palestine Refugees in the Near East (UNRWA) is a relief and human development agency which supports more than 5 million registered Palestinian refugees, and their descendants, who fled or were expelled from their homes during the 1948 Palestine catastrophe as well as those who fled or were expelled during and following the 1967 Six Day war. UNRWA provides education, health care, and social services to the population it supports. Aid is provided in five areas of operation: Jordan, Lebanon, Syria, the Gaza Strip and the West Bank, including East Jerusalem.

Inclusive Education: Inclusive education is a right-based approach to education, one which appreciates the diversity of all learners and caters for their needs placing particular emphasis on the needs of children vulnerable to exclusion and marginalization. Inclusive education requires improving education systems to become more responsive to the needs of all students (UNRWA, 2013). Consequently inclusive education requires a shift from a medical model, that focuses on individual students' deficits' assuming special services and staff, are required, towards a social model that addresses attitudinal and environmental barriers to learning and participation, acknowledging that meeting students' needs is a shared responsibility.

Vulnerability refers to the physical, social, economic and environmental factors that increase the susceptibility of a community or individuals to difficulties and hazards and that put them at risk as a result of loss, damage, insecurity, suffering and death

Neglect is the failure of parents, caregivers, the community and society to meet a child's physical and emotional needs when they have the means, knowledge and access to services to do so or failure to protect the child from exposure to danger.

Abuse is a deliberate act (single or persistent) of ill treatment that can harm or is likely to cause harm to a child's safety, well-being, dignity and development. Abuse includes all forms of physical, sexual, psychological or emotional ill treatment

Exploitation is a general term referring to the use of children for someone else's advantage, gratification or profit, often resulting in unjust, cruel and harmful treatment of the child. These activities are to the detriment of the child's physical or mental health, education, moral or social-emotional development. This covers manipulation, misuse, abuse, victimization, oppression and ill treatment

\section{Historical Background}

The old societies had a mythical view of the interpretation of disability; Abdul Rahman, A. (1994) referred to a number of tragedies committed against the disabled: People have attributed the abnormality of creature formation to metaphysical powers or illogical perceptions. The earliest record of such cases is what was found on a pottery plate discovered in Iraq, dated back to about 2000 BC, that is, during the reign of Assyria in Nepal, the king of Nineveh, in which some 
cases of the creatures' licentiousness and the birth of these cases were described as a harbinger of the one who brought them to life or it is an indication of the wrath of the gods. Thus it was usually normal kill the abnormal baby and his/her mother thinking that this is so satisfying to the gods. Taking into account that primitive man was most interested in the search for food, there was a difficulty of the status of disabled people, because they were unable to participate in the collection of fruits, fishing, as well as the complete inability to defend themselves. Therefore, the disabled or those with special needs in these societies were subjected to a kind of genocide for those who see them as unable to do anything as well as their inability to contribute to their society. However, it was different in the Pharaonic civilization, where many historical analyses reflect the interest of kings and Pharaohs of social welfare of the special groups. For example, Ramses I and other Pharaohs gave remarkable attention to the care of the poor, orphans, widows, the disabled and the needy in general. This was supported by the nature of the religious role of the priests in the process of organizing social and religious relations with attention to the so-called special groups of society (Abdul Rahman, 1994: p. 85).

The Greek era was similar to the tragic age. Plato called for the elimination of children with disabilities by killing them; in order to preserve the purity of the human element in his republic. In Sparta, the children with disabilities were overwhelmed. They have carried the child after his birth to a certain place to be examined by the elderly of the tribe. If they find the child's body strong, they raise him and give him a piece of land but if he is weak, he is thrown a way out of the tribe area.

In the Middle Ages, the emergence of religions and the values of justice, tolerance, equality and the right of everyone to live. The church allowed this group to live under their care. Monasteries took care of such communities. The Duke of Bavaria asked to establish a house for the blind in 1178 and tried to train them (Lotfi, 1978). Islam did not ignore this category of people, the role of the Islamic Group in caring for them and supporting them "Cooperate with righteousness and piety, and do not cooperate in sin and transgression." (Holy Quran, Al-Maida, verse 2). Even Messenger Mohammad asked Muslims to help the disabled and those who need help. Additionally, Islam denies the deviation from the blind, lame and patient.

Mohammad Husain Ajami (2007) states that those who are in need were treated differently during the historical eras as follows:

1) The stage of extermination: This stage represents the killing and annihilation of every disabled person, because he cannot protect himself or his tribe and Plato supported the idea in his book (the Republic).

2) The stage of ignorance: This stage represents throwing the people with disabilities in isolated or uninhabited areas, leaving them with no care or attention i.e. to get them die slowly.

3) The stage of institutional care: The reason for the emergence of this stage is the existence of heavenly religions that have thought of the disabled or people 
with special needs as people who are deprived of one of their properties, and therefore we must be sympathetic to them. During this stage, shelter were provided for the weak and disabled people in the monasteries, taking care of them mentally and psychologically.

4) The stage of training and rehabilitation: This stage represents the reconsideration of the disabled, and that they are human beings with all the rights but they lack one or more mental processes or skills. Therefore, they must be trained and rehabilitated so as to participate actively in preserving their life and contribute to develop their community like others.

In the 1980s, 1981 it was declared the International Year of Disabled people. The theme was equality and full participation, and international treaties such as the Universal Declaration on Education for All. The United Nations Convention on the Rights of the Child in 1990. The Universal Declaration of Human Rights in 1993, as well as the Declaration of Intent from the Sub-Regional Seminar on Planning and Organizing Special Needs Education in 1993 and the Universal Declaration on Special Educational Needs in 1994, which affirmed the need for universal primary education for all age groups. (Hussein Al-Ajmi, 2007, 15-16).

Recently, the interest of inclusive education in terms of concept and practice has been increased, considering that inclusive education represents the reform programs of the educational process in all countries. It is considered as a basic strategy for dealing with sources of exclusion, marginalization and exclusion. Inclusive education process supports Diversity among all learners, aiming at transforming schools and other learning centres into places that serve their needs (Abdel Bari 2016). Inclusive education also supports all children, their equality, social justice regardless of their cultural backgrounds, mental abilities, their social type and disability type and their economic, social, health and psychological conditions. This is based on Inclusive education of the World Declaration on Education for all adopted at Jomtien, Thailand (1991): All children, adolescents and adults shall have the right to benefit from education without discrimination or exclusion. "Education for all" is one of the basic issues that helps societies in the elimination of marginalization and exclusion based on race, color, sex or religion, as well as Ethnic origin and social diversity. Also, inclusive education is one of the essential components of learning by improving the learning process and providing a high quality educational service which meet the needs of the learner. Effective teaching methods and strategies should be used to help educate children for 55 million primary and uneducated children in the world. In addition to 554 million people who lack the basic skills. In addition, a large number of people attend school but do not have a good education (UNESCO, 2012)

\section{What Is Inclusive Education?}

Inclusive education revolves around the child and the child-friendly environment. Inclusive education is a reality as every learner is different from other learners and has different strengths and needs of his own. A child needs special 
help in a subject and has a disability in another subject. A learner may have a physical disability to be able to enter a classroom but he shows an improvement in learning certain subject. Some children may not be able to get high grades but they can become professional artists or professional athletes or contribute effectively in their school and community.

Norwegian Refugee Council (2013)

UNESCO defines inclusive education as the process of responding to diversity of the needs of all children, adolescents and adults so as to provide their needs through participation in learning and integration in the cultural and social context. Additionally, to reduce the exclusion phenomenon in education and learning.

UNRWA (2013) defines inclusive education is the method to ensuring that all Palestinian refugee children have equal opportunities to learn in their schools and receive adequate support to get them achieve their full potential, regardless to gender, ability, disability and health status.

Oberti (2014) argues that inclusive education contains four basic elements:

1) It is essential a search for the most appropriate ways to respond to diversity try to learn how to learn from differences and differences.

2) Is linked to the use of multiple strategies to stimulate students' creativity and ability to deal with problems and resolution.

3) The right of the child to attend school, to express his or her views and to obtain educational expertise Good and get valuable educational results.

4) To include Moral responsibility and to give priority to children who are exposed to marginalization and exclusion.

Initial steps are also being taken across the region to improve Inclusive Education and provision for children with Special Educational Needs (SEN). Although all UNRWA host countries have much progress still to make in this area, growing recognition of the importance of Inclusive Education means that implementation of such programmes is likely to increase over the coming years. A focus on changing the way teachers teach will similarly align with a greater emphasis on Inclusive Education. Quality education must be accessible for all UNRWA students and to this effect the importance of an Inclusive Education approach, supported by a Policy, and the development of diagnostic and learning tools to identify, and support children, with Special Education Needs (SEN). whether they are children who are highly able, or those with learning needs or physical disabilities is key. (Education Reform 2015: 8)

Although the region in general is yet to establish strong educational programmes that meet the needs of marginalised children and those with special educational needs, there is a growing recognition of the need for change. The West Bank and Gaza provide good examples of what UNRWA host countries are, at a minimum, aspiring to achieve in this area. The Palestinian Child Law of 2005 emphasises the government's commitment to provide education and training in special classes, schools or centres that. Are linked to the regular education system; are accessible and in proximity to the child's residence; provide appropriate 
types and levels of education; and have staff who are educationally qualified to educate children according to their needs. The oPt also has separate, special schools for deaf and blind children, and one for physically handicapped children. However, the Universalia review (2010) found that, in practice, potentially less than $10 \%$ of children with SEN are receiving appropriate support. (ibid: 25)

The United Nations Relief and Works Agency for Palestine Refugees in the Near East (UNRWA) is committed to providing quality inclusive education which respects the rights and appreciates the diversity of all children. UNRWA aims to remove barriers to access and create equal opportunity for learning and participation in order to enable all Palestine refugee children to realize their full potential regardless of their gender, abilities, disabilities, socio-economic status, health and psychosocial needs.

\section{Why Inclusive Education?}

Inclusive education represents the values, policies, and practices that support the right for every child to be included in a classroom, regardless of his ability, and to allow children to participate in all activities. Inclusive education removes barriers and discriminatory attitudes toward disability that can be formed by local culture and school policies. It goes beyond integrating students from special schools into mainstream schools and is more than addressing "special educational needs" emerging from a disability or difficulty in learning. Inclusion is about comprehensive education, equity, and belonging-inclusive education is about all the students.

Inclusive education identifies that students have diverse needs, and have the right to a response to these needs through child-centered education. This right may be supported through changes in curriculum or learning materials and styles, and collaboration from inside and outside schools to ensure equal, effective, and efficient practice of education for all.

As a result of continuous conflict in the region, the number of people with disabilities has increased in Palestine. In 2011, a Palestinian Central Bureau of Statistics survey found that $7 \%$ of the overall population of Palestine had a disability, although there is no accurately updated database recording information on children with disabilities.

Palestinian attitudes toward disability can be varied, many taking either the medical or charity model approach. In the medical model, people with a disability are seen as the problem and are expected to adapt to the environment. The charity model portrays people with a disability as tragic figures who need to be helped. They also are perceived as having no active role or power within their own lives. Palestinian people with disabilities are demanding a change from such stereotypes, and seek to be more socially included through removal of barriers to participation in the environment and adoption of an inclusion ethos that emphasizes a more rights-based approach. Such a social model is essential to protect the right to quality education and access, to resources and support, and to real participation in schools Alshakhshir (2017). 


\section{Inclusive education in Palestine:}

The Palestinian Ministry of Education and Higher Education (MoEHE) has, from its birth, aimed to provide education to all children regardless of their diverse and varying needs. Faced with scarce specialized human and material resources, the ministry elected inclusive education (IE) to address these needs as this would utilize the already existing schools and staff (MoEHE, 2015).

In 1997, the MoEHE, with the help of a number of non-Palestinian organizations, piloted inclusive education (education that excludes no child regardless of her/his challenges and that takes into account students' individual differences and the diversity of their needs). Inclusive education counselors were trained and appointed in twelve Palestinian directorates, awareness meetings were held with students, teachers, parents and directors, teachers of the participating schools were trained, schools were equipped with the necessary resources and efforts were made to make the buildings and the school environments more welcoming. By the end of the pilot phase, 89 schools were involved.

In the year 2000, the MoEHE adopted IE as a general program to be implemented in all schools between 2006 and 2007, during which it facilitated the registration of many students with a range of additional needs in mainstream classrooms. The support available for these students was inadequate (for many reasons, including: lack of support staff in some schools, numbers of students per class, curriculum density and its disregard for diverse learners, lack of teacher training, lack of policy). This was addressed by assigning a teacher from each participating school to act as a mediator between the school and the directory and to see to it that the students' needs were being met.

In 2014, an Inclusive Education policy was drafted and launched and is currently being adapted to accommodate the feedback of the participants and stakeholders Sheikha (2016).

Inclusion in Ministry of Education and Higher Edcuation (MoEHE) and UN:

Inclusive and child-friendly education has been identified as a current priority by the MoEHE, together with early childhood development, to receive further UN support.

Inclusive and Child-Friendly Education brings together Child-Friendly Schools (CFS) and Inclusive education (IE) to strengthen the MoEHE's capacity to provide quality education to all Palestinian children. Inclusive Education (IE) programmes and Child-Friendly Schools (CFS) refers to the classroom and the whole school and making sure all children are in school and actively involved in learning. Quality learning responds to the individual needs of each child. Inclusive and child-friendly classrooms and schools will look different from district to district, and from school to school, however they are all based on the same three principles (or dimensions):

1) Child-centred Effective with, and healthy and protective of children.

2) Democratic Participatory of children, parents, families and communities.

3) Inclusive Embraces diversity of abilities and backgrounds among students 
as well as promote gender equity and sensitivity.

Nine UN agencies(FAO, UNDP, UNFPA, UNICEF, UNRWA, UNSCO, WFP and WHO, coordinated by UNESCO, have been supporting the Ministry of Education and Higher Education in Palestine through the UN/MoEHE "Education for All" Package on inclusive and child-friendly education and early childhood development which aims at strengthening the capacities of the Ministry and education personnel to promote quality basic education for all children, regardless of their gender, abilities, disabilities, backgrounds and circumstances. This Package is responding to the MoEHE's goals to increase access and retention of school-aged children in the education system and improve the quality of teaching and learning. Pilot implementation is done through public and UNRWA schools in the West Bank, including East Jerusalem, and in Gaza. These schools benefited from a school feeding programme; different capacity development programmes focusing on ICT in Education, inclusive and child-friendly education as well as special educational needs; innovative education programmes on EFA and educational leadership were designed and implemented as part of the development of pre-service teacher courses, benefiting school principals, teachers and supervisors. Plans have been developed with partner universities in Gaza to improve the relevance of teacher education programmes in order to prepare student teachers to better address the diverse needs and abilities of children. This includes components on special educational needs such as psychosocial support. Moreover for the first time in Palestine, the Ministry of Education and Higher Education opened Grade 0 classrooms (one year pre-school before grade 1) in some of the pilot schools.

The EFA Package will be further implemented with the support of OFID and AGFUND with a focus on capacity development at institutional and teacher training levels, as well as on efforts to improve linkages between schools and communities, particularly through child-led activities and innovative teaching and learning.

The EFA Package has been fully integrated in the first UN Development Assistance Framework (UNDAF) for Palestine. The Education component of the UNDAF, coordinated by UNESCO, contributes largely to the implementation of the EFA Package for the next three years. Among the main achievements is the increased awareness on inclusive and child-friendly education within UN agencies, MoEHE, universities and civil society organizations. Without establishing inclusive and child-friendly education systems, Palestine will not be able to reach the EFA goals. Three core elements of Child-Friendly Schools (CFS) UNESCO office in Ramallah (2017).

\section{Previous Studies}

A study for Dash (2018): Problems and Challenges of Inclusive Education for Students with Special Needs. This research study examined the problems and challenges of inclusive education programme for students with special needs 
at primary education level. The objectives of the study were to examine the problems faced by teachers in inclusive education and to study the barriers to inclusion. The main focus of the study was to obtain suggestions from the headmasters, teachers to enhance the effectiveness of inclusive education and efficiency of teachers. The data was collected from 270 teachers and 50 headmasters from schools of selected districts of Orissa through purposive sampling. In the present study teachers were asked to indicate the problems they face while working in inclusive setting. The teachers have reported lack of confidence to teach in inclusive settings, lack of training in inclusive education, no feedback from supervising officers about what they are doing, adapting the curriculum to the needs of special needs children, problem of establishing linkage with special schools, lack of adequate leadership from headmasters and problem of mobilizing the community to participate in inclusive education programme. Some other problems faced by regular teachers are: lack of support from colleagues, providing resource room help, lack of parental involvement and managing behaviour problems of special needs children.

A study for Singh (2016) entitled: Inclusive Education in India: Concept, Need and Challenges. This study investigates Inclusive Education (IE) as a new approach towards educating the children with disability and learning difficulties with that of normal ones within the same roof. It brings all students together in one classroom and community, regardless of their strengths or weaknesses in any area, and seeks to maximize the potential of all students. It is one of the most effective ways in which to promote an inclusive and tolerant society. It is known that 73 million children of primary school age were out of school in 2010, down from a high of over 110 million out-of-school children in the mid-1990s, according to new estimates by the UNESCO Institute for Statistics (UIS). About Eighty percent of Indian population lives in rural areas without provision for special schools. It means, there are an estimated 8 million children out of school in India (MHRD 2009 statistics), many of whom are marginalised by dimensions such as poverty, gender, disability, and caste. Today, what are the needs and challenges for achieving the goal of inclusive education? How will an inclusive environment meet the needs of children with disabilities? How quality education can be effectively and efficiently delivered for all children? Therefore, inclusive schools have to address the needs of all children in every community and the central and state governments have to manage inclusive classrooms. Keeping in view these questions, this article discusses in detail the concept of inclusive education, including importance, challenges and measures to implement inclusive education in India.

Similarly, Chimwaza (2015) in his study entitled: Challenges in Implementation of Inclusive Education in Malawi: A Case Study of Montfort Special Needs Education College and Selected Primary Schools in Blantyre, explored the challenges faced in the implementation of inclusive education in Malawi. The study was constructed within Bronfenbrenner's ecological systems theory. The theory maintains that children grow, develop and learn in a complex 
environment that impacts them negatively and positively. An exploratory qualitative case study research design was adopted for the study. Purposive sampling technique was used to pick on the study sites as well as the research participants. Montfort Special Needs Education College and a few selected primary schools formed the cases for the study. Semi-structured interviews and focus group discussion were used to collect data and results analyzed using themes with a clear focus on the research questions. The findings of the study indicated that teacher training is one of the main intervention measures used by Montfort SNE College in promoting inclusive education learning environments. Teachers are the most important personnel in the implementation and transforming educational policies. Other interventional measures done by Montfort SNE College include: research on inclusive education, and awareness creating. The challenges identified included; inadequate trained teachers, cultural beliefs and lack of political goodwill in investing in inclusive education.

Petrović (2013), in his study which entitled: Implementation of the Inclusive Educational Model in School, deals with the potential of the school context in the process of implementation of the inclusive model of education as an integral part of reforming the school system. This work shows the significance of the legal regulations, as a base framework for the introduction of inclusion into schools. From a critical aspect, matters are analyzed and considered, regarding their potentials of the school context in the realization of the goals and tasks of inclusion. The central part of this work is about the real possibilities of schools to answer the need and the challenges of the reformation of the school system in the area of inclusive education, and in a sense, analyzing the advantages, strengths and weaknesses that comprise the everyday life in schools. Through the example and analysis of theoretical examinations and research on introducing inclusion into the school praxis up to now, the necessary changes in the school context are pointed out. Thus, we conclude that the implementation of inclusion makes for the starting grounds to create an inclusive society, wherein changes in schools are a priority.

\section{Methodology}

The current study followed the qualitative approach as it leads up to deep understanding to the phenomenon.

The Study sample: Ten UNRWA schools were chosen randomly from the middle area of the Gaza Strip. 30 Teachers were interviewed; three teachers were purposively chosen from each school.

\section{The study instrumentation:}

The researcher used a teachers' interview: (30) teachers were chosen randomly from the sample schools: the interview questions were six. The interview questions were as follows:

1) Is there a support team for the inclusive education initiative? What are their roles? 
2) How did you get the ability to deal with this initiative? Who helped you?

3) Did you employ the tools of the initiative effectively in your school?

4) What improvements do you suggest for employing this initiative effectively?

5) What are the obstacles that face the employment of this initiative?

6) What are the needed tools to support this initiative?

\section{Results}

\section{Q.1 Is there a support team for the inclusive education initiative? What are their roles?}

All the study sample members responded positively to this question. Teams were formed in all the schools. Their role was to:

- Following up the students with additional needs.

- Forming a strategic inclusive school plan.

- Supporting teachers to form individual plans and employing inclusive education.

- Supporting students psychologically and educationally.

Q.2 How did you get the ability to deal with this initiative? Who helped you?

All the study sample members said that they got a workshop implemented by the Education department in UNRWA to train teachers to use the initiative tools.

1) Twenty-one teachers added that the school administration held meetings with them of the mechanism of employing the tools 1 - 19 with the help of the support team.

2) Twenty-five teachers said that school principals supported and trained them. Ten teachers said that the special needs specialist helped them. Six teachers said that the school counsellor is the one who trained them.

\section{Q.3 Did you employ the tools of the initiative effectively in your school?}

All the study sample members said that they employed the initiative effectively. Also, they recorded this in a portfolio for this purpose.

\section{Q.4 What improvements do you suggest for employing this initiative ef-}

\section{fectively?}

The answers were different regarding how to improve the initiative, the answers could be summed up as follows:

1) Sufficient training about the IE.

2) Employing various class strategies and tools for the SAN students.

3) Providing the teachers with all the facilities.

4) Implementing demonstration lessons about IE.

5) Co-operating with the next-door schools about the initiative.

6) Following up the initiative by the school administration, Education specialists and other stakeholders.

7) Providing all the facilities to schools.

8) Hosting the community experts to support this initiative. 
9) Providing support teachers to help other teachers at school.

10) Providing success stories regarding the initiative.

11) Providing leaflets and pamphlets regarding the initiative.

Q.5 What are the obstacles that face the employment of this initiative?

All the study sample members responded to the questions, their answers were similar to some extent. The obstacles could be summed up in the following lines:

1) Teachers are overloaded.

2) Classes are overcrowded.

3) Lack of support to the students with additional needs.

4) Lack of allocated time to the students with additional needs.

5) Man students' guardians lack how to support their children.

\section{Q.6 What are the needed tools to support this initiative?}

The study sample members answers were as follows:

1) To provide LCD for classrooms.

2) To provide suitable equipments for students of additional needs.

3) To provide schools with care units.

4) To co-operate with local institutes regarding caring about students especially the ones with additional needs.

5) To provide schools with special activities rooms for the additional needs students.

\section{Discussion}

Inclusive Education was shown in the previous years in different titles and names and even the idea was sometimes different. Integrating students who are disable and able in the same class are different from including them together. Even mainstreaming students who are disabled are different too. Inclusive education is possible when the educational opportunities are provided to all students including the children with special needs. Several studies in the field of inclusive education point to teacher education and school leadership as essential for the implementation of inclusive education in the classroom. Yet many teachers need more awareness and training in this field. Agbenyega (2007) states that several regular education teachers who feel unprepared and fearful to work with learners with disabilities in regular classes show frustration, anger and negative attitude toward inclusive education since they believe that it could lead to lower academic standards. However, a "special needs" focus and a lack of training for management, combined with teaching training methodology do little to alter the classroom status quo, especially when responsibility is shifted onto a specialist resource teacher rather than methods altered to suit all students. Researchers have found that inclusion is inadequately addressed and often neglected in teacher training. Thus, in this study, the researcher tried to spot the light on how eudcators apply what they have been trained on in the UNRWA premises and how they implemented what they have learnt. Results showed that the programs given to these educators were implemented to some extent. This may attribute to 
some factors such as the lack of monitoring, or even the lack of teachers' awareness. In many cases, teachers showed positive attitude and this may be attributed to their inner willingness to learn and to help other people. In other cases, we found the teachers can apply the inclusive practices in their classes but in an incorrect way.

\section{Recommendations}

1) Sufficient training for school staff about the IE initiative and the employment of tools.

2) Activating the support team role to help the IE initiative in schools and provide the facilities.

3) Preparing training lessons for the IE initiative.

4) Lowering the loads of teachers and lowering the number of the students in classes.

5) Providing the schools with support teachers.

6) Providing the community members with suitable training regarding the IE initiative.

7) Providing competitions for success stories.

\section{Conflicts of Interest}

The author declares no conflicts of interest regarding the publication of this paper.

\section{References}

Abdel Bari, M. (2016). Inclusive Education. Cairo: Cairo University.

Abdul Rahman, A. (1994). Inclusion-A Way to a Better Life. Cairo: Cairo University.

Abdul-Mohsen, A. (1987). Inclusive Education. Cairo: Cairo University.

Agbenyega, J. (2007). Examining Teachers' Concerns and Attitudes to Inclusive Education in Ghana. International Journal of Whole Schooling, 3, 41-56.

Ajami, M. (2007). Inclusive Learning. Cairo: Al-Azhar University.

Alshakhshir, R. (2017). Inclusive Education in Palestine. A Journey for Everyone. http://www.childhoodexplorer.org/inclusive-education-in-palestine

Chimwaza, E. (2015). Challenges in Implementation of Inclusive Education in Malawi: A Case Study of Montfort Special Needs Education College and Selected Primary Schools in Blantyre. Master Thesis in Diakonia and Christian Social Practice.

Dash, N. (2018). Problems and Challenges of Inclusive Education for Students with Special Needs. Online International Interdisciplinary Research Journal, 8, 155.

Lotfi, A. (1978). Exclusion as a Community Phenomenon. Cairo: Al-Azhar University.

Petrović, Z. (2013). Implementation of the Inclusive Educational Model in School. Facta Universitatis Series: Philosophy, Sociology, Psychology and History, 12, 29-40.

Rodriguez, J. (2019). Exploring the Challenges and Benefits to Inclusive Education in Jordanian UNRWA Schools. Multiple Voices for Ethnically Diverse Exceptional Learners, 19, 44-57.

Sheikha (2016). Inclusive Education in Palestine. Ministry of Education. 
https://www.childhoodexplorer.org/inclusive-education-in-palestine

Singh, J. (2016). Inclusive Education in India: Concept, Need and Challenges. SRJIS Bimonthly, 3, 3222.

UNESCO (2017). Inclusive Education in Palestine. Ramallah.

http://www.unesco.org/new/en/ramallah/education/inclusive-education

UNRWA (2011). UNRWA Reform Strategy. 2011-2015 HQ. Amman.

UNRWA (2012). Inclusive Learning: A Way forward Inclusive Education Policy (2013) UNRWA. Amman. http://www.unrwa.org/ar/resources

UNRWA (2013). UNRWA Strategy-Inclusive Education. HQ Amman. 